\title{
Test and analysis for ventilation system of Hongtoushan underground mine
}

\author{
Jingxian Liu ${ }^{1, a}$,Ning Mao ${ }^{1, b}$, Xiaosong Chen $^{1}$ and Deqiang Chang ${ }^{1, \mathrm{c}}$ \\ ${ }^{1}$ College of Resources and Civil Engineering, Northeastern University, Shenyang,110004,China

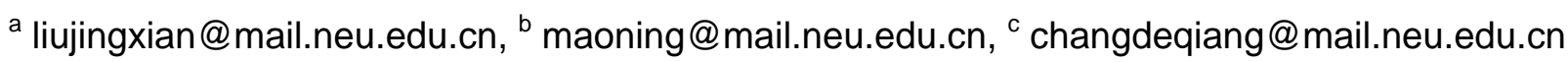

Keywords: Mine, ventilation system, test, optimization.

\begin{abstract}
For Hongtoushan underground mine with long history, it is important to master the actual state of complex ventilation system for simulating and optimizing. In this paper, the parameters of ventilation system are tested. The results show the volume in different level are quite different, from $6.78-17.78 \mathrm{~m} 3 / \mathrm{s}$, the function of fan at upper position is not obvious, and there are air leakage at the upper mined-out area.
\end{abstract}

\section{Introduction}

Hongtoushan copper mine is located in northeastern China, that is Fushun city, Liaoning Province. After 50 years of exploration, the depth of the mine reach to $1200 \mathrm{~m}$. There are 18 levels now, i.e. $+253,+193,+133,+73,+13,-47,-107,-167,-227,-287,-347,-407,-467,-527,-587,-647,-707$, $-767,-827$. The top three levels become nearly the mined-out area. Because of the ventilation network is long, wind volume in deep level is not enough, two fans installed in $-287 \mathrm{~m}$ (west) and $-476 \mathrm{~m}$ (east) level, forming series system with the upper fans respectively. The multi-stage station ventilation system is useful for complex mine ventilation[1-3].

The ventilation system of Houtoushan mine composed with: inlet tunnel by No.1 big shaft and No.1 small shaft, transfer to all levels along the way in. At levels of $-407 \mathrm{~m},-476 \mathrm{~m}$ and $-527 \mathrm{~m}$, transfer from No. 1 big shaft to No.2 big shaft, and send the fresh air to the down levels. Return air are transferred by two main exhaust fans located in east and west position.

Because of the long history, large ventilation system and complex wind condition,the test for ventilation system parameters will help to improve and optimize the system[4-5].

\section{Test plan}

Test and analysis for all running parameters of exiting ventilation system such as air volume, wind speed, air temperature, air humidity and ventilation resistance at work area and horizon level tunnel are useful for simulating, optimizing and improving of ventilation system. The ventilation system of hongtoushan mine is shown in figure 1 . Test content is as follows:

(1)Total volume

(2)Volume of two inlet shaft and all level tunnels, the wind speed and area of tunnels

(3)Volume of outlet level tunnels, the wind speed and area of tunnels

(4)The parameters of two relay fans in down position of $-287 \mathrm{~m}$ (west) and $-476 \mathrm{~m}$ (east), such as volume, wind speed, resistance, power

(5)Volume assigned to working level such as $-467 \mathrm{~m},-527 \mathrm{~m},-587 \mathrm{~m},-647 \mathrm{~m}$, tunnel's parameters such as size, wind speed, wind direction, temperature and humidity.

(6)Volume and pressure of main fan at ground surface.

(7)Wind speed, wind direction, temperature and humidity at exit of west and east main fans.

(8)Wind speed, temperature, humidity air pressure at entrance of east fan at level of -467 with two east fans running or only east fan at -467 level running. 


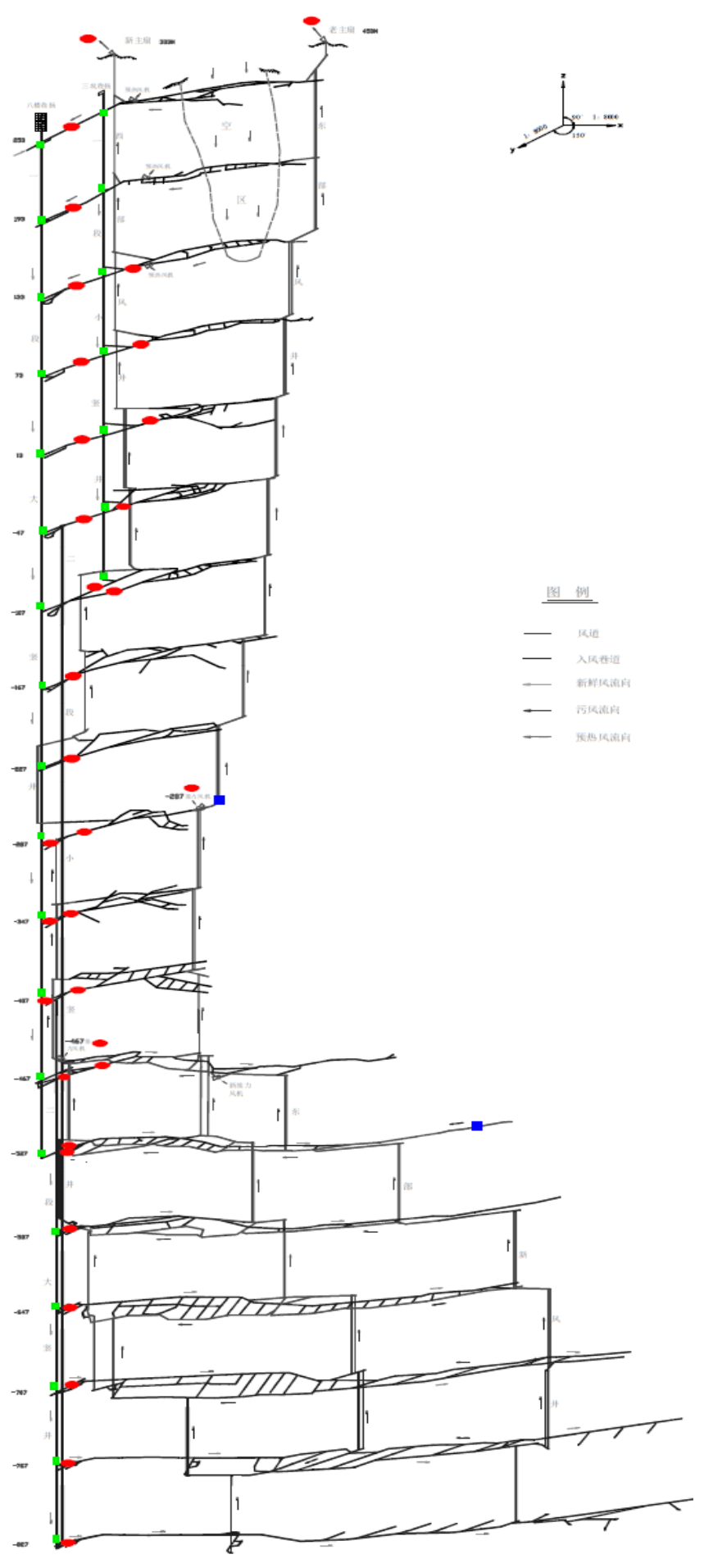

Figure 1 Ventilation system of Hongtoushan underground mine

\section{Data analysis}

Volume test of level tunnel People are divided into five groups, testing in different level at the same time. The test position and method are similar for different level. Figure 2 is plane plan of tunnel and test position. 


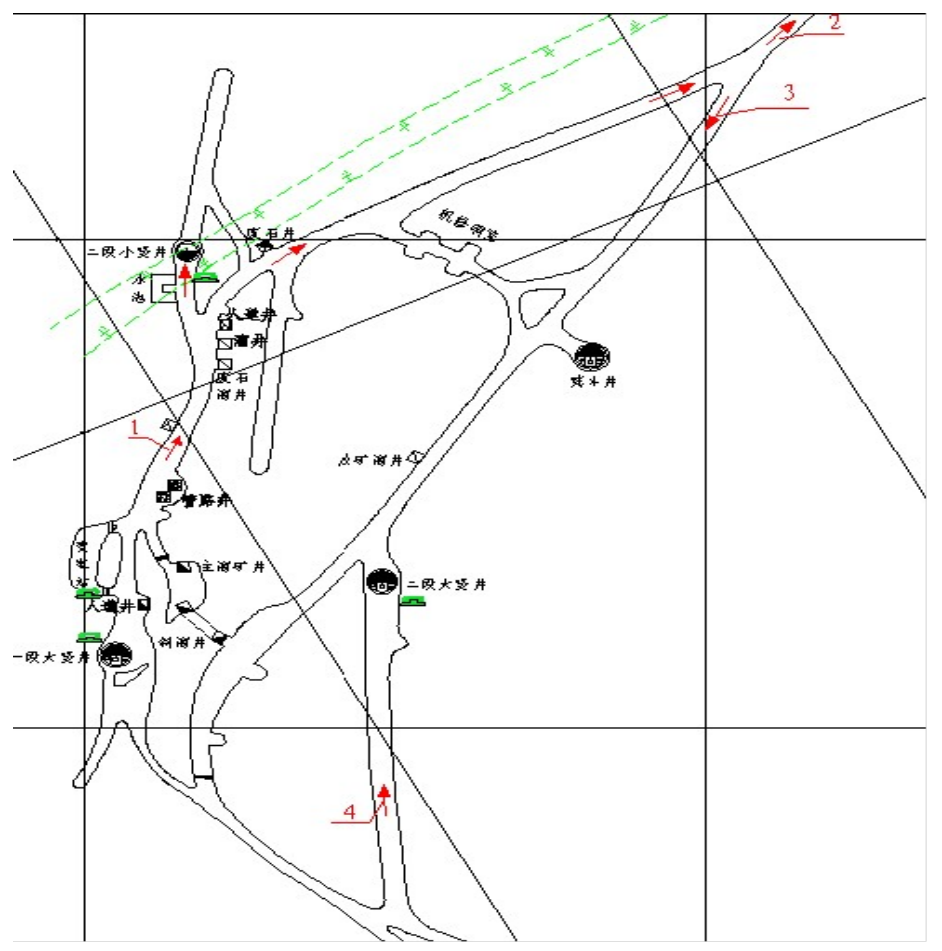

Figure 2 Tunnel plane plan of -467 level

The figure 2 show that fresh air go through No.1 shaft. Part of air go down to levels below -467 , and another part of air go into the level of -467 , the volume is $6.78 \mathrm{~m} 3 / \mathrm{s}$.

Volume of all level at normal running state At normal running state, i.e. West fans at ground surface and east fan at -467 level running together, the data of ventilation system listed in table 1 .

Table 1 volume for all levels at normal running state

\begin{tabular}{|l|l|l|l|l|l|l|l|l|}
\hline level & $-467 \mathrm{~m}$ & $-527 \mathrm{~m}$ & $-587 \mathrm{~m}$ & $-647 \mathrm{~m}$ & $-707 \mathrm{~m}$ & $-767 \mathrm{~m}$ & $-827 \mathrm{~m}$ & total \\
\hline volume $(\mathrm{m} 3 / \mathrm{s})$ & 6.78 & 6.44 & 13.78 & 13.31 & 14.56 & 15.69 & 15.78 & 86.34 \\
\hline
\end{tabular}

East fan on ground surface The fan located on mountains about 500 meters above sea level, air temperature is $4.9 \mathrm{C}$,humidity is $57.7 \%$. Fan model is DK45-6, air volume is $30.4-78.3 \mathrm{~m} 3 / \mathrm{s}$, wind pressure is $1400-2759 \mathrm{~Pa}$, power is $132 \mathrm{kw}$, the speed of $980 \mathrm{r} / \mathrm{min}$. At the condition of this fan run only, the wind speed test and listed in table 2.

Table 2 wind speed of east fan on ground surface

\begin{tabular}{|l|c|c|c|c|c|c|}
\hline position & 1 & 2 & 3 & 4 & 5 & Average \\
\hline wind speed(m/s) & 13.4 & 17.8 & 14.5 & 17.2 & 13.0 & 15.18 \\
\hline
\end{tabular}

The average wind speed is $15.18 \mathrm{~m} / \mathrm{s}$, air volume is $58.1 \mathrm{~m} 3 / \mathrm{s}$, temperature at fan exit is 20C, humidity is $100 \%$ with fog. Static pressure of fan is $2200 \mathrm{~Pa}$

West fan on ground surface The west fan is located at about $300 \mathrm{~m}$ above sea level with the same model as east fan.At the condition of this fan run only, the wind speed test and listed in table 3.

Table 3 wind speed of east fan on ground surface

\begin{tabular}{|l|c|c|c|c|c|c|}
\hline position & 1 & 2 & 3 & 4 & 5 & Average \\
\hline wind speed(m/s) & 12.1 & 15.0 & 13.2 & 15.4 & 12.3 & 13.6 \\
\hline
\end{tabular}

The average wind speed is $13.6 \mathrm{~m} / \mathrm{s}$, air volume is $51.67 \mathrm{~m} 3 / \mathrm{s}$, temperature at fan exit is 20C, 
humidity is $100 \%$ with fog. Static pressure of fan is $1950 \mathrm{~Pa}$.

Return air of $\mathbf{- 4 6 7}$ level under different fan running state Under the condition of both east fans running, i.e. East fans at ground surface and at -467 level, total air volume is $71.96 \mathrm{m3} / \mathrm{s}$; when the fan at level -467 running only, air volume is $73.24 \mathrm{~m} 3 / \mathrm{s}$. The volume only -467 fan running is greater than the volume both east running. Partly because the leakage between -467 level to ground surface, or partly because the air from west shaft go east shaft through -467 level, which affect the volume of east fan.

Under the condition of both west fans running, total air volume is $27.05 \mathrm{~m} 3$ / s. Return air of west shaft is not good, most of the return air undertaken by the east shaft.

Data analysis Normal running state is the west fan at ground surface and the east fan at -467 level running together. The data show that the total volume of 7 levels below -467 is $86.34 \mathrm{~m} 3$, and the volume of west fan at -467 level is $73 \mathrm{~m} 3$, so there are $13 \mathrm{~m} 3$ air are pumped by east fan. The volume of down fan is $51 \mathrm{~m} 3$, which indicate that this fan pump more air from mined-out area, the efficiency is low.

\section{Conclusion}

From the test and analysis, the conclusions are listed below:

1)The air volume at different level are change in a large scope between $6.78-17.78 \mathrm{~m} 3 / \mathrm{s}$, the total volume below -467 level is $86.34 \mathrm{~m} 3 / \mathrm{s}$.

2)The volumes at level of -467 and -527 are small, volume at down level are great, which indicate the throttle control is good.

3)The total volume of 7 level is $86.34 \mathrm{~m} 3 / \mathrm{s}$, the volume of east fan at -467 level is $73 \mathrm{~m} 3 / \mathrm{s}$, which indicate east fan pumping most the air, and the remaining $13 \mathrm{~m} 3 / \mathrm{s}$ is pumped by the west fan.

4)The volume of east down fan is $73 \mathrm{~m} 3 / \mathrm{s}$, at the same time, the east fan at ground surface do not running, there are some fog at the exit of fan, which indicate the wind speed is very small. Part of air is pumped by west fan at ground surface, the remaining diffuse by empty area.

\section{References}

[1]ZHANG Shuchuan, Ventilation Resistance Measurement Method and Error Analysis of Mine Ventilation System[J]. Mining Safety \& Environmental Protection,2014,2. In Chinese.

[2]WANG Wencai, WANG Junfeng, etc., Resistance Measurement and Optimized Plan of Ventilation System in Wangchao Mine[J].Coal Science and Technology,2012,40(2).In Chinese.

[3]LI Yuqian, LI Yuyuan, Test and study on mine ventilation[J]. Coal Mine Modernization , 2012.6:36-38. In Chinese.

[4]DENG Zengshe, SI Junhong, etc. Fast Regulation and Optimization Technology of Production Mine Ventilation System[J]. Coal mine safety, 2014,7:48-52. In Chinese

[5]ZHANG Xianfeng, GU Liang, etc., Study on Venlilation System Resistance Measurement of Donghuantuo Coal Mine[J].JOURNAL OF NORTH CHINA INSTITUTE OF SCIENCE AND TECHNOLOGY,2010,07(4). In Chinese.

\section{Acknowledgement}

It is a project supported by the National Science and technology support program(2013BAC01B02) and the national high technology research and development program (863 Program)

(2013AA065101). 